\title{
Research on Language Environment and Language Planning in Xi'an
}

\author{
Qin Wang \\ School of Foreign Languages, Shaanxi Normal University \\ Xi'an, China
}

\begin{abstract}
The research is designed to explore language environment and language planning in Xi'an. The paper reports the basic situation of language environment in Xi'an based on literature research and personal observation. The research findings show that the city has made impressive achievements in foreign language environment construction since official guidance was released in 2010 . However, there are still some issues worth thinking about. The paper discusses some existing problems in current language environment from the points of official guidance and public language service. Since $\mathrm{Xi}$ 'an is aiming at transforming from a provincial center to an international metropolis, language planning will face more challenges in the future. The paper also offers some suggestions for future language planning. The suggestions are in the following aspects: status and function planning, research on language planning, standardization and public language service.
\end{abstract}

Keywords-Xi'an; Language planning; Language service; Standardization

\section{INTRODUCTION}

Xi'an has a long history of being the capital of Shaanxi Province and the center of Northwest China. It's honored as the World Historic City by the UNESCO in 1981. The city is now rapidly growing into an international metropolis with a registered urban population of over nine million according to 2017 data. The development strategy of Belt and Road Initiative was adopted in 2013 to enhance regional connectivity and mutual understanding. Xi'an is in the core area of the strategy, which means both opportunities and challenges for the city's development. In recent Development Planning of Guanzhong Plain issued in 2018, it's clearly stated that Xi'an will be supported to develop into a national central city, an international transportation center and an international city with historical and cultural characteristics.

On its way to an international metropolis, Xi'an has a large number of things to do, among which language planning is an element of critical importance. Language is regarded as a soft environment for the development of the city. It is different from the traditional hard environment, like building, roads, etc.; however, it definitely has undeniable importance for the development of this city.

This paper is triggered by the controversy on the media after the Xi'an official guidance for language environment construction was issued in 2010. It focuses on current language environment of Xi'an, the existing problems, and from the point of language planning, explores the possible approaches to

The paper is sponsored by 2018 program of Shaanxi Association of Social Sciences, "Research on International Language Environment Planning and Cultivation in Xi'an"(2018C080). language environment improvement. The paper mainly includes three parts: the importance of language planning, language environment in $\mathrm{Xi}$ 'an, and approaches to improvement.

\section{IMPORTANCE OF LANGUAGE PLANNING}

In the literature concerned with "language planning", Weinar Haugen is mentioned as the first person to introduce and define the concept. He is also the one who introduces the concept to China[1]. Since then, language planning has been widely discussed on the national level and a large amount of research findings have been achieved in status planning and corpus planning. It is deliberate effort to influence the function, structure or acquisition of languages or language variety[2]. It's usually done by the national government.

In recent years, with speeding urbanization in China and the unexpected expansion of large cities and the related language issues, function of language planning in city level has been noticed and discussed. Based on the existing findings on status planning and corpus planning, Li Yuming proposes to carry out language function planning and divides language function into several levels[3]. Some researchers take the language planning thought to the regional level. There are papers discussing language planning in some cities, like Hongkong, Macau, Shanghai, etc. $[4,5,6]$. When Belt and Road Initiative is widely discussed, language is thought necessary and effective in advancing the development of Belt and Road Initiative. It is pointed out that language communication is foundation and precondition of the "Five Communications" in the Belt and Road Initiative[7]. It's also claimed that language is a prerequisite for the Belt and Road Initiative[8].

Harmonious language life is an important issue in contemporary urbanization[9]. In terms of city planning, language planning should be enlisted as a basic and critical element for making the city livable, unique and international. Language environment partly accounts for overall environment, image, openness and vitality of a city. From this point of view, it's irreplaceable for the development of Xi'an on its way to a world city.

With migration and other issues in urbanization, urban language life is getting complicated. It is not just a problem of language but a combination of social, psychological, and cultural issues. To some extent, language could influence everyone's everyday life in a modern city. 
When a visitor comes to a new city, language is probably the first thing to soothe his anxiety and gives him sense of safety. When a migrant or an immigrant lives in a new city, language is a necessity for him in both individual and social life. Even for a native speaker, he has great possibility of meeting some unexpected challenges in language life.

\section{LANGUAGE ENVIRONMENT IN XI'AN: ACHIEVEMENTS AND THOUGHTS}

The government of Xi' an released an official guidance for international language environment construction of the city in 2010. It lists the approaches to cultivate English language environment in five years. According to Xi'an Evening, Xinhua Net and some other media, it's a controversial issue at that time because it requires the people of all careers to learn English and reach a certain level in five years. In addition, the assessment and evaluation of the requirements are not clear and the understanding of international language environment is obviously confined to English language environment in the guidance.

Even though the guidance has some limitations, there is no doubt that a lot of efforts have been made and the foreign language environment of the city is improving in different aspects.

In 2013, the International Language Environment Construction Committee was established by The Office of Foreign and Overseas Chinese Affairs of the Xi'an Municipal People's Government. Now we can see the following improvements in recent years.

In terms of research, a giant step has been taken in Xi'an. Xi'an Collaborative Innovation Center for the Silk Road Language Services has been set up in Xi'an International Study University. According to the website of Shaanxi Education Bureau, the official website of Shaanxi Belt and Road Language Service Center has been available online since July, 2017. It also includes a multilingual calling center which offers multilingual interpretation service.

In terms of public language service, the following are obvious improvements:

(1)For public signs, bilingual or multilingual public signs are greatly improved in tourist spots, especially the well-known tourist attractions. The public signs on the road and in other public places are also better designed with fewer grammatical and translation errors.

(2)For emergency help, according to Xi'an Evening, 110, 119 and 120 began to offer English and Korean language services since 2016. And the latest news on ifeng.com reports that Xi'an 110 center started its nine-language service since May, 2017, which means the calling to 110 in a foreign language will be transferred to a corresponding volunteer and the tripartite conversation mode will help 110 operator understand the caller and make a quick response.

(3)For e-government service, the bilingual websites of Xi'an Municipal People's Government and Shaanxi Provincial People's Government are available online. The very noticing point is that Xi'an Municipal People's Government website offers the function of accessibility browser, which makes the website accessible to the people with visual difficulty in online reading.

(4)For public transportation, the key points like the Xianyang International Airport and the newly built metro lines all have well-designed audio and visual bilingual system. Many traditional public transportation lines could offer bilingual auto stop announcements. The public transportation junctions also provide some bilingual services.

According to what have been mentioned above, the achievements in language environment are surely impressive; however, we have to notice that there are still a lot of things needing to be done on the road of building a good language environment.

Aiming at transforming from a provincial center to an international metropolis, language planning in $\mathrm{Xi}$ 'an has the following points worthy of thinking.

(1)rom the point of governmental guidance, taking international language environment simply as English environment is not enough. Language environment refers to all the languages in city life. The critical step for language planning in Xi'an is to have a diversity understanding, which means making clear that international language environment does not simply refer to the issues related to foreign language environment. It is not just connected with one or several foreign languages. International language environment is not English language environment. It refers to creating a harmonious language environment for all the people living in the city. It is not a simple issue of asking citizens of all fields to have a certain kind of English proficiency. It is an issue related to all the languages and dialects used in the city. In order to construct harmonious language environment in Xi'an, we have to have a clear mind on status and function of all the languages and dialects used in the city. Then we could sensibly deal with the complicated language issues arising one after another in this rapidly growing city.

(2)Public language service is an important part in language planning. It covers almost all the aspects of city life.

From foreign language service point, a paper sponsored by program of Xi'an Social Science Fund Program of 2015 points out that international students are not satisfied with language service in $\mathrm{Xi}$ 'an[10].

Furthermore, we have to understand public language service in a city does not equal to service to foreigners and does not equal to public signs or translation service for business and conferences. It covers a large range of areas in all aspects of city life, like language assistance, language education, language resources, emergency language service, language products, etc.

Public sign is a small but useful part in public language services. In Xi'an, public signs in places of interests and other public places still need improvement. Mistakes in translation are seen in spelling, collocation, punctuation, capitalization and some other aspects related to language function and communication[11]. Translating and naming system of public 
signs in different places and different areas also need to be standardized to decrease confusions.

For public transportation, the visual and audio designing of bilingual or multilingual systems still need improvement. The language system of metro lines could be improved in terms of language and user-friendliness. The buses usually have no visual bilingual stop announcements and the audio announcements are often not clear enough due to background noises and the quality of facilities. The city bus stations and some long-distance inter-city bus stations are not well designed from the perspective of language service.

For some important occasions like banks and hospitals, it's useful to encourage all the employees to have certain level of language proficiency. But the solution does not lie in here. The problem is that we don't have clear guidance for those who need linguistic help in foreign languages, dialects and special languages. From the point of English, it's not easy and not necessary for everyone to speak English for communicating in public occasions like banks, stores, taxies, etc. The most important thing is to offer comprehensible guidance or navigation map to show the procedures like which counter to go or where to seek language help. From the point of communication, the public-service involved units may need a system to mark foreign language speaker which will make seeking help easier.

For emergency help, many numbers need multilingual service. Now 110 center already started 9-language calling service while 120 and 119 services are limited to three languages. Making all the numbers multilingual probably needs a long time and a lasting devotion. Maybe we could think about some other quick solutions, like a one-number multilingual calling center for all kinds of emergencies. Since multilingual calling center is largely based on volunteer service, we have to think about establishing a comprehensive volunteer system to make sure the calling center runs normally all the time. The existing multilingual interpretation calling center is offering multilingual interpretation service but it is charged by seconds. We still need free multilingual interpretation service like other international metropolises in the world.

Based on the above thoughts on language environment achievements and the research findings about language problems of the city, the paper is going to discuss some approaches to improve language environment.

\section{APPROACHES TO IMPROVEMENT}

$\mathrm{Xi}$ 'an is on the fast lane of urbanization and internationalization. The function and orientation of the city is totally different from before. In the coming future, the city will expand its urban area and the population will keep growing. More visitors from all over the world will come to the city. More migrants and immigrants will choose to live in the city. The city is responsible for building and managing harmonious living environment for everyone.

In this background, the city will face many issues in language perspective. As a rapidly growing city with an urban population of over nine million, the city will have complicated issues in language planning. For language planning, the following needs to be considered:

\section{A. Status and Function Planning: Diversity and Harmony}

According to Law on the Standard Spoken and Written Chinese Language of the People's Republic of China, the normalization and standardization of standard spoken and written Chinese language should be promoted to make it play a better role in public activities. From this point, the city needs to obey the law and promote the standard Chinese language in language environment planning.

Mother language cannot be ignored in the name of building foreign language environment or internationalizing the city. It is our own language and culture that makes us our city unique, special and charming.

On this basis, the situation, status and functions of different languages and dialects should be clear on official agendas. Language planning is not for terminating diversity. Language planning needs the view of resource, economy, diversity and development. From this point, language planning for Xi'an needs the consideration of many different aspects. Language planning for Xi'an is supposed to follow the national law and at the same time localize in accordance with the city's requirements and developments.

As a result of internationalization, more foreign languages will be more frequently and extensively used in public life. For foreign language environment, diversity and harmony consideration is also important. English will be the most important foreign language in general. It will be widely used in static and dynamic public language communications. At the same time, as some foreign-language communities are arising, some foreign languages will be used as both $\mathrm{H}$-language and Llanguage in certain areas to provide necessary language surroundings and language services, like Korean in the planned Xi'an International Community in Xi'an Hi-Tech Industrial Development Zone. In these areas, the necessary foreign language services need to expand from public signs to more aspects in daily life, like medical services, language education, etc.

For dialects, the resource view should be adopted. We have to notice that dialects are also a part of the city's language life and a part of the city's resource and attraction from cultural and economic point. Dialects are closely related to relics, cultural life, and city development. Language contact and mutual influences will be an important part in language research. Some traditional dialect districts or communities will no longer exist while the new ones will appear. Even some dialects will not be seen everywhere in public life, they are still in some areas or families.

In the national language reform and planning guidance for 2012-2020, "serving special group" is mentioned as a key job in the future work schedule. Since the city has some people with low language proficiency or language impairments, future language planning needs to give them enough care. The people with language impairments need special care in medical therapy, education, and also public places. The public places like transportation systems which mainly include metro and bus lines need to consider audio and visual impairment in the process of designing. For example, in Tokyo, public transportation signs have Braille versions. The consideration of 
language details will make the city more livable for the people with language impairments.

From the point of aging society, the city is aging with over 1.5 million people over sixty in 2018 according to $\mathrm{Xi}$ 'an Evening. And the number is growing each year. The senior citizens also need language assistance in public and private life or they will be confronted with a lot of problems which will greatly limit their individual activities. Language planning in Xi'an needs to have some special consideration for senior citizens.

\section{B. Language Planning Research}

The existing research center like Xi'an Collaborative Innovation Center for the Silk Road Language Services is working on some programs related to language situation and language services. It's obviously not enough for the city's future development.

In Language Environment Planning for Beijing(2011-2015), many aspects are mentioned, like foreign language assessment, standardization, multilingual service, volunteer, foreign language media, foreign language education.

In consideration of this, language planning research of $\mathrm{Xi}$ 'an has a long way to go. The city needs a general center for research on language planning. The city also needs a language monitoring system to make clear of language issues all the time. The research is supposed to include but not be limited to language planning, language situation, language emergency, language education, language assistance and language standardization. The research findings will help the city improve its language environment and language life.

\section{Standardization}

The ignorance of standardization could be easily seen in the current public signs. If Dayanta is Wild Goose Pagoda in one translation and Dayan Pagoda in another, it will definitely lead to confusion. From the point of translation, the standardization of public signs, public names and terms should be done.

Beijing issued its local rules for standardizing English translation of public signs and Guidelines for English translation of organization names and professional titles in 2007 and 2008. The book Enjoy Delights: The English Translation of Chinese Menus, which models how to translate menus, was published in 2011. Shanghai also issued its two standards in 2009 and 2010. These standardizations are great assistance for standardizing translations in all kinds of public areas.

Xi'an also needs this kind of translation standardizations. To standardize all the translations of names, places, menus, etc will help to form a coherent and understandable public signing and naming system.

Besides translation, standardization also has some other aspects to cover. It needs to consider all the aspects of language use and all the language users. All the language systems need to use the same standard. For example, the map, the metro system, other public transportation systems like bus lines should adopt the same standard for naming and translating. If the metro system uses Wei Yi Jie as the station name, while
Weiyi Street and some other names are used in other transportation systems or maps, there is a problem for finding or naming the right place or station. If we have a standardized system, like an esay-to-understand, consistent numbering or coding system, many language inconveniences will be avoided.

Furthermore, language standardization is not just for tourist spots and not just for translation. The language life in a city needs to follow some standards and rules. If we take language as an important element in city planning, the necessary local standards will be helpful in cultivating language environment of the city.

\section{Public Language Service}

Language service is a gradually accepted concept in modern life. Public language service is a very general topic. It refers to all kinds of services with written and spoken language, language technology and language products[12]. A smart city is supported by language service and language service is indispensable content of city development [13].

For public signs, the bilingual signs in places of interests and other public places still need improvement in term of translation and linguistic landscape. Standardization is necessary. Public signs in different places and different areas need to be standardized for convenience and understanding of all the people living in the city. Based on the improvement in bilingual signs, some signs may need to be multilingualized. And language for special group of people should be used in public signs. More public signing systems and linguistic landscapes like navigation map and language assistance marking systems need to be designed for banks, hospitals, public libraries and some other places.

And very importantly, public signing system needs to consider all the individuals in city life, not just foreigners. The foreigners, the migrant workers, the seniors, the special group of people all need to be cared in designing public signing system. And the signing system is not limited to public transportation and tourist spots. Many public places need appropriate signing, such as the hospitals, the public libraries, the government offices, the theaters, the cinemas, the schools, the shopping centers.

Language education service includes both in-school language education and out-of-school public language programs, like the programs for promoting language efficiency of low-income urban residents or the programs for migrant workers. And language education should appropriately deal with all the languages in use, like Chinese, foreign languages, dialects, and language for special group of people. From this point, Chinese language education and promotion programs are also important in language planning. Sign language is also an important part for the city's language life. Sign language awareness should be systematically introduced to middle schools, high schools and universities. The corresponding volunteer programs should be set up for a long run.

For e-service, we need more technology involvement for building a smart city for all language users. Language element is an important consideration when a comprehensive or integrated website or App is designed. The whole smart-city system needs language elements to support. 
A multilingual city also needs multilingual emergency language service. The existing multi-number calling service and the multilingual interpretation service is not enough. We may think about a one number multilingual calling center or a special agency for providing emergency language services for all kinds of emergencies involving medical needs, safety consideration, conflicts, etc .

Xi'an is suggested to develop into a center of traditional and international culture [12]. When the city is developing into an international metropolis, it will be a center for cross-culture communication. From this point, the city's public language service needs the view of culture and cross-culture communication.

Language planning should consider culture communication and promotion. Language is closely related to culture. Language itself is culture. Chinese language and Chinese culture has many possibilities to be known and understood in an international metropolis.

From this point, we have the chance and responsibility to promote Chinese language and Chinese culture. Some language training programs could be designed for Chinese language learning or Chinese culture understanding. Language elements could be used in designing, decoration, tourism and some other aspects of city life.

We may provide appropriate information and culture insights to English audiences on the media level. Shanghai, Beijing and Guangzhou all have local English newspapers and English channels or programs. Xi'an could also make good use of media to promote Chinese culture and cross-culture understanding. It will also help the audiences to integrate into local life and communities.

Since Xi'an is going to play an important role in Belt and Road Initiative, the city needs more linguistic professionals for Belt and Road Initiative.

The city needs to be clear of language-related fields and their requirements for language professionals. The foreignlanguage programs in universities and colleges need to be well designed to prepare some professionals for future.

And more volunteers are needed. The city needs a complete volunteer system, well-organized and dependable. They will serve in all kinds of important occasions, and very important, they will serve in communities for everyday life.

\section{CONCLUSION}

The present study introduces Xi'an and its language environment. Xi' an is an important communication and culture center in history, and now it is transforming from a provincial center to an international metropolis. In this process of transforming, the city has an urgent need for language planning.

Even though the guidance of 2010 has some limitations, the city has made some impressive achievements since then. For research, special Committee and Innovation Center were set up. For public services, public signs, emergency calling assistance, e-government services, public transportation are all improved from the point of language.
When we are encouraged by the improvements, there are some issues worthy of thinking.

Based on current situation and challenges of language environment in Xi'an, the paper proposes some possible approaches to language environment improvement. From the status and function point, standard language needs to be promoted in the city's language planning. At the same time, foreign languages, dialects, language for special groups need to be appropriately planned so that harmonious language life could be achieved. From the research point, language planning research and standardization research, as basis of language planning, are important for all aspects of city life. From the service point, public language service covers a wide range of issues in city life. Everyone should be cared in language service system. In addition, public language service has the responsibility to promote culture communication and crossculture understanding. The city also has the requirement for all kinds of language professionals and dependable volunteers.

\section{REFERENCES}

[1] X. Guo, "Cause and effect of language project - based on realization of Chinese-project practice in late century," Journal of Xinjiang Normal University(Social Sciences), Vol 34, pp.34-40, 2013. (In Chinese)

[2] K. B. Robert, and R. B. Baldauf Jr., "Language planning from practice to theory," Clevedon: Multilingual Matters ltd., 1997.

[3] Y. Li, "A discussion of language function planning," Applied linguistics, Vol 1, pp.2-8, 2008. (In Chinese)

[4] P. Wang, "The sociolinguistic situation and six approaches to language planning - the issue of the medium of instruction in Chinese courses in Hongkong," The Journal of Chinese sociolinguistics, Vol 1, pp.81-87, 2004. (In Chinese)

[5] Y. Sheng, "Language situation and language planning in Macau," Dialect, Vol 4, pp.298-306, 1999. (In Chinese)

[6] M. Zhang, R. Zhang, "Diversity and harmony: language planning in the development of Shanghai," Journal of Yunnan Normal University(Humanities and Social Sciences), Vol 43, pp.25-32, 2011. (In Chinese)

[7] Y. Li, Belt and Road needs language to pave the way, People's Daily, September, 2015. (In Chinese)

[8] J. Lu, "Languages: A Prerequisite for the Belt and Road Initiative, Studies on Cultural Soft Power," vol. 1, 2016. (In Chinese)

[9] C. Liu, "The construction of urban harmonious life based on the contemporary context," Urban Studies, Vol 20, pp.1-5, 2013. (In Chinese)

[10] L. Li, C. Liu, "Language Life Satisfaction Promotion Strategy for International Students in Xi'an," New West, May, 2017. (In Chinese)

[11] Y. Zhang, X. Song, J. Ji, "Language environment from the perspective of public signs in Xi'an, " Technology and Economic Guide, Vol 12, pp. 172-175, 2017. (In Chinese)

[12] Y. Li, "Language Service and Language Industry", East Journal of Translation, Vol.8, pp.4-8, 2016. (In Chinese)

[13] H. Wang, "Implications and the assessment framework for urban public language services," Journal of Yunnan Normal University(Humanities and Social Sciences), Vol 50, pp.58-64, 2018. (In Chinese)

[14] S. Wang, "My suggestion for constructing Xi'an into an internationally metropolitan city," Journal of Chang'an University(Social Science Edition), Vol 13, pp.7-15, 2011. (In Chinese) 